\title{
BMJ Open Alcohol-related presentations to emergency departments in Ireland: a descriptive prevalence study
}

\author{
Brian McNicholl, ${ }^{1}$ Deirdre Goggin, ${ }^{2}$ Diarmuid O’Donovan ${ }^{2,3}$
}

To cite: McNicholl B, Goggin D, O'Donovan D. Alcohol-related presentations to emergency departments in Ireland: a descriptive prevalence study. BMJ Open 2018;8:e21932. doi:10.1136/ bmjopen-2018-021932

- Prepublication history for this paper is available online. To view these files, please visit the journal online (http://dx.doi. org/10.1136/bmjopen-2017021932).

Received 25 January 2018 Revised 19 March 2018 Accepted 2 May 2018
Check for updates

${ }^{1}$ Emergency Department, Galway University Hospitals, Galway, Ireland

${ }^{2}$ Department of Public Health, Health Service Executive, Merlin Park, Galway, Ireland

${ }^{3}$ School of Medicine, National University of Ireland Galway, Galway, Ireland

\section{Correspondence to} Dr Diarmuid O'Donovan; diarmuid.odonovan@nuigalway. ie

\section{ABSTRACT}

Objectives To determine the prevalence of alcoholrelated presentations in all 29 emergency departments (EDs) in Ireland and compare with non-alcohol-related presentations in order to identify opportunities for improvements in the quality of patient care and related data collection.

Design and setting Descriptive prevalence study reviewing all records in the same four 6 -hour periods in every 24-hour ED in the country.

Participants 3194 persons who attended EDs over four specified 6-hour periods.

Primary outcome measures The prevalence of alcoholrelated presentations, comparison with non-alcoholrelated presentations and the categorisation of these presentations according to WHO International Statistical Classification of Diseases and Related Health Problems 10th Revision codes.

Results The total number of presentations was 3194 in the four 6-hour periods, of whom 189 (5.9\%) were alcohol related, varying from $29.0 \%$ in the early hours of Sunday morning to $1.2 \%$ on Monday morning ( $p>0.0001$ ). The alcohol-related presentations were more likely to be men, attend on early hours of Sunday morning, arrive by ambulance, leave before being seen by a doctor or leave against medical advice; and they were less likely to be admitted to hospital.

Conclusions Alcohol-related presentations are a significant burden on EDs and ambulance services, especially in the early hours of Sunday mornings. Addressing the alcohol-related burden on EDs requires improvements in data collection and information systems, the development of appropriate interventions and related referral services and better preventive actions for alcoholrelated harm.

\section{BACKGROUND}

Alcohol consumption in excess of the national recommended guidelines ${ }^{1}$ is the norm in Ireland with almost $40 \%$ of adults binge drinking at least once a month. ${ }^{2}$ A national survey found that $75 \%$ of the alcohol consumed was part of a binge drinking session. ${ }^{3}$

Emergency departments (EDs) respond to many of the consequences of alcohol-related (AR) harm but knowledge of the prevalence

\section{Strengths and limitations of this study}

This is the first Irish national prevalence study of the burden on alcohol-related presentations to emergency departments (EDs) that included all EDs in the country.

- This is the first study in Ireland that allows comparison of alcohol-related attendance with non-alcohol-related attendances.

- Data were collected retrospectively by reviewing ED records.

- It covers four 6-hour periods in December-January which may not reflect seasonal variations.

of AR presentations is limited to localised or single-site studies. ${ }^{4-6}$ There is no nationally agreed systematic way of counting AR presentations, of screening for AR harm or of early intervention.

Legislation on alcohol is currently being debated in Ireland ${ }^{7}$ : this aims to reduce alcohol consumption and reduce AR harm. The proposed legislation includes actions on prices, restriction on sales and warning labels. It is an offence to sell alcohol to anyone under the age of 18 under current licensing law. Bars and pubs typically operate during the following hours: Monday to Thursday, 10:3023:30; Friday and Saturday, 10:30-00:30; and Sunday, 12:30-23:00. A pub or bar can extend these opening times by making applications to the Court for special exemptions. Nightclubs close at 02:30 from Monday to Saturday and 01:00 on Sundays. Off-licence sale of alcohol is permitted between the hours of 10:30 and 22:00 on weekdays and 12:30-22:00 on Sundays. 8

The main objective of this study was to assess the scale of $\mathrm{AR}$ presentations to all EDs in Ireland. We developed a pragmatic method of investigating such presentations in a nationally representative study in the same selected time periods, with the intention of informing policy makers and developing 
systematic processes for future use to improve the quality of data collection and care provided.

\section{METHODS}

All full-time EDs in public hospitals in Ireland, defined as providing service 24 hours/day every day, were invited to participate. As data are collected and stored in different ways in these EDs, a standardised data collection template was designed and piloted in one ED. Clinical staff members were identified as the nominated survey coordinator in each ED through members of the Irish Association of Emergency Medicine-the majority of Consultants in Emergency Medicine in the country, including at least one in every hospital, are members. The coordinator's role was to retrospectively examine the records of people who attended at agreed specified times on specified dates and record all presentations on the standard survey template. Data collected included sex, age, time of arrival in ED, method of arrival, category of injury, medical condition, any reference to alcohol, intoxication, mental health problems, social problems, admitted to hospital or not and referral outcome.

The dates and times were chosen to broadly represent times that are busy and quiet as AR presentations are likely to vary by time of day, week and season. Following consultation with ED colleagues, we chose: Sunday, 11 December 2015, between 00:00 and 05:59; Wednesday, 14 December 2015, between 12:00 and 17:59; Friday, 6 January 2016, between 18:00 and 23:59; and Monday, 16 January 2016, between 06:00 and 11:59. The site coordinators were emailed the survey instrument and the list of definitions of AR presentations with detailed instructions on how to collect data and a telephone contact for any queries. Any ED record with a reference to alcohol was classified as an AR presentation, and any record without reference to alcohol as not alcohol related (NAR) (box 1). Clinically intoxicated and other AR presentations were defined using International Statistical Classification of Diseases and Related Health Problems 10th Revision (ICD-10) ${ }^{9}$ codes and the definitions of AR presentations used in the Australasian study of AR presentations to EDs. ${ }^{10}$ That study used a different method of data collection: a snapshot of all AR attendances at one time.

Data were returned in an Excel spreadsheet by email and analysed in a public health department using SPSS. Where data were not returned in a timely manner, sites were contacted by telephone and email to maximise response rates. Descriptive statistics were produced and comparisons were done using $\chi^{2}$ and t-tests. We report

\section{Box 1 Identification of Alcohol Related presentations}

Any ED patient record with a reference to the words 'alcohol', 'alc' or ' $\mathrm{C}_{2} \mathrm{H}_{5} \mathrm{OH}$ ' was classified as an alcohol related (AR) presentation, and any record without a reference to alcohol as not alcohol related (NAR). on aggregate data only to maintain site and individual confidentiality.

\section{Patient involvement}

Patients were not involved in the design or conduct of this study.

\section{RESULTS}

All 29 EDs in public hospitals in Ireland were invited to participate, and all agreed. The three paediatric-only EDs in the country participated and are included in the analysis. The 29 EDs identified 3194 patients over the four specified 6-hour periods: 189 (5.9\%) of whom had a reference to alcohol recorded in the notes, meeting our criterion for AR presentation. Individual hospital data are not presented: AR presentations ranged from $0 \%$ to $20 \%$ in the different hospitals. The busiest 6 -hour period in terms of AR presentations was the early hours of Sunday morning when 108 (29\%) of 372 presentations nationally had a reference to alcohol in the ED notes. Of the AR patients presenting early on Sunday, $63.2 \%(\mathrm{n}=86)$ were categorised by clinical staff as intoxicated, compared with $20.6 \%$ on the study on Friday evening, $12.5 \%$ on Wednesday afternoon, and $3.7 \%$ on Monday morning.

When compared with NAR patients, the AR presentations were more likely to be men (72.5\% compared with $49.6 \%)$. The AR group ranged in age from 11 months to 85 years (mean 39.1, median 36.0) with $10(5.3 \%)$ aged under 18 years: the mean age in the NAR groups was 39.0, median 37.0. The method of arrival to ED was by ambulance for 108 of the AR presentations (57.1\%) compared with 413 of $3005(13.7 \%)$ in the NAR group ( $<<0.00): 86$ $(63.2 \%)$ of the AR group who were categorised as intoxicated came by ambulance, whereas $22(41.5 \%)$ of those who were not intoxicated came this way. In the early hours of Sunday morning, the proportion of AR presentations arriving by ambulance ( 74 of $108,68.5 \%$ ) was higher than any other time period studied.

The descriptive information in table 1 summarises the data on all the people who presented to all the EDs in Ireland at the specified times on the study days. The majority were discharged home or to general practitioner (GP) follow-up: only one patient in our study was identified as having been referred to specialist alcohol services. Coincidentally, the numbers in the AR and NAR groups in age bands 20-29 and 30-39 are the same.

A significantly higher proportion (9\%) of AR presentations left before being assessed by a doctor compared with other presentations $(3.6 \%), \mathrm{p}=0.001$, as was the proportion who took their own discharge against medical advice $(7.9 \%)$ compared with others $(0.5 \%), \mathrm{p}<0.000$. However the proportion of people admitted to hospital among the AR presentations $(17.5 \%)$ was significantly less than the proportion of NAR presentations (26.5\%), $p=0.006$. When we compared patients classified as AR to NAR patients by whether they were intoxicated or not, 13 $(9.6 \%)$ of the intoxicated group left before being seen 
Table 1 Descriptive information on people attending all EDs in Ireland over four 6-hour periods

\begin{tabular}{|c|c|c|c|c|}
\hline & Alcohol Related (AR) n(\%) & Not Alcohol Related (NAR) n(\%) & Total n (\%) & Significance $p<0.05$ \\
\hline All & $189(5.9)$ & $3005(94.1)$ & $3194(100)$ & \\
\hline \multicolumn{5}{|l|}{ Sex } \\
\hline Female & $52(27.5)$ & 1439 (47.9) & $1491(46.7)$ & \multirow{2}{*}{$p<0.0001$} \\
\hline Missing/unknown & $0(0)$ & $75(2.5)$ & $75(2.3)$ & \\
\hline \multicolumn{5}{|l|}{ Age (years) } \\
\hline $18-20$ & $8(4.2)$ & $70(2.3)$ & $78(2.4)$ & \multirow[t]{6}{*}{$\dagger$} \\
\hline $21-29$ & $43(22.8)$ & $350(11.6)$ & $393(12.3)$ & \\
\hline $30-39$ & $43(22.8)$ & $350(11.6)$ & $393(12.3)$ & \\
\hline $40-49$ & $33(17.5)$ & $285(9.5)$ & $318(10.0)$ & \\
\hline $50-59$ & $26(13.8)$ & $284(9.5)$ & $310(9.7)$ & \\
\hline Missing/unknown & $2(1.1)$ & $73(2.4)$ & $75(2.3)$ & \\
\hline \multicolumn{5}{|l|}{ Day/time } \\
\hline Sunday 00:00-05:59 & $108(57.1)$ & $264(8.8)$ & $372(11.6)$ & \multirow[t]{4}{*}{$p<0.0001$} \\
\hline Monday 06:00-11:59 & $11(5.8)$ & $903(30.0)$ & $914(28.6)$ & \\
\hline Wednesday 12:00-17:59 & $31(16.4)$ & $1160(38.6)$ & $1191(37.3)$ & \\
\hline Friday 18:00-23:59 & $39(20.6)$ & $678(22.6)$ & $717(22.4)$ & \\
\hline \multicolumn{5}{|l|}{ Method of arrival } \\
\hline Ambulance & $108(57.1)$ & $413(13.7)$ & $521(16.3)$ & $\mathrm{p}<0.0001^{*}$ \\
\hline Garda (police) & $3(1.6)$ & $0(0)$ & $3(0.1)$ & \multirow[t]{2}{*}{$\dagger$} \\
\hline GP referral & $14(7.4)$ & $948(31.5)$ & $962(30.1)$ & \\
\hline 2: Very urgent treatment & $43(22.8)$ & $665(22.9)$ & $708(22.9)$ & \multirow{5}{*}{$\dagger$} \\
\hline 3: Early full assessment & $115(60.8)$ & $1494(51.4)$ & $1609(52.0)$ & \\
\hline 4: Needs to be seen but can wait & $25(13.2)$ & $627(21.6)$ & $652(21.1)$ & \\
\hline 5: Can be seen elsewhere & $1(0.5)$ & $45(1.5)$ & $46(1.5)$ & \\
\hline Missing/unknown & $0(0)$ & $8(0.3)$ & $8(0.3)$ & \\
\hline \multicolumn{5}{|l|}{ Outcome } \\
\hline $\begin{array}{l}\text { Discharged home/referred } \\
\text { to GP }\end{array}$ & $82(43.4)$ & $1271(42.3)$ & $1351(42.4)$ & \multirow[t]{9}{*}{$\dagger$} \\
\hline Referred to outpatient clinic & $20(10.6)$ & $292(9.7)$ & $312(9.8)$ & \\
\hline Left before assessment & $17(9.0)$ & $108(3.6)$ & $125(3.9)$ & \\
\hline Left against medical advice & $15(7.9)$ & $14(0.5)$ & $29(0.9)$ & \\
\hline Admitted to hospital & $33(17.5)$ & $797(26.5)$ & $830(26.0)$ & \\
\hline $\begin{array}{l}\text { Referred: Medical Assessment } \\
\text { Unit }\end{array}$ & $0(0)$ & $15(0.5)$ & $15(0.5)$ & \\
\hline Transfer to other hospital & $0(0)$ & $9(0.3)$ & $9(0.3)$ & \\
\hline Other & $12(6.3)$ & $91(3.0)$ & $103(3.2)$ & \\
\hline Unknown & $9(4.8)$ & $408(13.6)$ & $417(13.1)$ & \\
\hline
\end{tabular}

*Under 18 compared with all other age groups/Ambulances compared with all other methods of arrival.

†Numbers too small to compute significance.

EDs, emergency departments; GP, general practitioner. 
compared with $4(7.5 \%)$ of those who were not intoxicated: the corresponding figures for those who self-discharged against medical advice were $9(6.6 \%)$ and 6 $(11.3 \%)$.

The diagnostic classifications of the 189 patients whose presentation was AR are summarised in table 2: 132 $(69.8 \%)$ of them were clinically intoxicated. Almost half of this group, 88 persons (46.6\%) had unintentional injuries, and $22(11.6 \%)$ had intentional injuries caused by a third party who was affected by alcohol. Many of the AR presentations had more than one condition.

\section{DISCUSSION}

Our study quantifies for the first time the extent of AR presentations to EDs nationally at both quiet and busy times, and provides evidence of the impact of alcohol on EDs and ambulance services. Published studies on AR presentations in EDs have used different methods in different populations ${ }^{11-14}$ with varying estimates of the rate from $1.2 \%$ in a Belgian study to $70 \%$ at peak times in a British study: our approach was pragmatic in the absence of a national data set and included the NAR group for comparison. The three paediatric-only EDs in Ireland are in Dublin: if we excluded the paediatric EDs, the proportion of AR presentations to all other EDs would be higher, but children make up part of the denominator in all the other hospital EDs. Eight of the 10 AR presentations in those under 18 years were aged $15-17$.

Many factors contribute to challenges in Irish EDs but it is clear that alcohol is a significant burden especially on Saturday nights-Sunday mornings. The impact of AR presentations on ED staff and other patients is likely to add to the stress on patients and staff, and challenge the quality of care provided. A particular concern is that more than half $(57.1 \%)$ of AR presentations were brought to ED by ambulance: a high proportion of these people either left before being assessed or took their own discharge against medical advice, which raises the issue of the use of limited emergency resources. The AR patients who were intoxicated were $50 \%$ more likely to come by ambulance. Intoxicated patients were also more likely to leave before being seen. However, most AR patients $(85 \%)$ were categorised by nursing staff as triage category 3 or higher, suggesting they were appropriate for treatment in an ED and were considered urgent at the time of assessment. Only one patient was categorised as suitable for assessment elsewhere (category 5). Differentiating intoxication from concussion, other forms of brain injury or overdose is not easy and erroneously attributing confusion or drowsiness to alcohol could have serious consequences. In one large US tertiary care centre, $1 \%$ of intoxicated ED patients who were initially assessed as low risk ultimately used critical care resources. ${ }^{15}$ There is no antidote or reversal agent for alcohol intoxication: time and clinical observation are essential. Training emergency service staff to work with patients with AR injury or illness at the scene
Table 2 Classification of alcohol-related presentations

Total n (\%)

Total alcohol-related ED $189(100)$

presentations

1. Direct Injuries

$109(57.7)$

a. Unintentional injuries, including road traffic 88 (46.6) injuries, drowning, burns, poisoning and falls

b. Intentional injuries, which result from $21(11.1)$

deliberate acts of violence against oneself or others

2. Intoxication $143(75.7)$

a. Alcohol involvement (blood alcohol $4(2.1)$

concentration) as determined by breathalyser

b. Clinical intoxication: reasonable suspicion 132 (69.8) of any caring health professional (includes triage nurse if not yet seen by a doctor) that a patient is affected by recent alcohol consumption

c. Intoxication, but unrelated to clinical presentation

3. Medical condition as the result of the harmful 65 (34.3) use of alcohol (ICD-10 code)

G31.2 Degeneration of nervous system due 2 (1.1) to alcohol

142.6 Alcoholic cardiomyopathy $1(0.5)$

K29.2 Alcoholic gastritis $11(5.8)$

K70 Alcoholic liver disease

$3(1.6)$

F10.2 Alcohol dependence syndrome $10(5.3)$

F10.3 Alcohol withdrawal state

$10(5.3)$

Other medical conditions that the treating $28(14.8)$

physician believes are attributable to or

exacerbated by alcohol (eg, Wernicke's

encephalopathy, Korsakoff's dementia,

cirrhosis, alcoholic hepatitis, hepatic

encephalopathy, Barrett's oesophagus/

Mallory-Weiss syndrome/peptic ulcer/chronic diarrhoea, infection)

4. Mental health $56(29.6)$

a. Mental health presentations due to alcohol 15 (7.9) intoxication

b. Mental health presentations due to harmful 15 (7.9) use of alcohol

c. Overdose involving alcohol alone or as a coingestant

\begin{tabular}{ll} 
5. Social problems & $49(25.9)$ \\
Z72.1 Problems of lifestyle: alcohol use & $49(25.9)$ \\
\hline 6. Indirect injuries & $22(11.6)$ \\
\hline $\begin{array}{l}\text { Intentional or unintentional injuries caused by } \\
\text { a third party affected by alcohol }\end{array}$ & $22(11.6)$ \\
\hline
\end{tabular}

of the first contact might reduce the numbers brought to ED and could directly benefit the patient and the ambulance service by reducing the frequent and regular callers known to have alcohol problems. ${ }^{16}$ 
We did not collect information on screening for alcohol in EDs; however, there is clear evidence that referral for brief intervention results in reduced reattendance at ED ${ }^{17}$ There is no nationally agreed process for screening in Ireland. It is notable that only one patient was recorded as having been referred to a specialist alcohol service: this reflects the limited availability of such services in many parts of Ireland, and the difficulty of discussing such a referral with patients most of whom were intoxicated $(75 \%)$ or in physical or emotional pain, at a time when EDs are busy.

The limitations of our study include that our data were collected in December-January which may not represent alcohol patterns at other times of year. This is usually a busy time in EDs in Ireland with winter pressures. Long waiting times can deter patients attending and increase the numbers leaving before assessment.

Collecting more precise data all year round would provide more accurate estimates of prevalence and incidence. There may be an underestimation of the AR burden: measurement error is likely to have occurred as some presentations may not have had a reference to alcohol recorded in the notes. There was a delay with data collection in some sites with more than one person collecting data. There may be an overestimation of AR presentations as some people who appeared to be intoxicated may have had symptoms due to other substances. A small proportion of intoxicated patients $(3.7 \%)$ had presentations unrelated to alcohol (eg, anaphylactic shock).

Reducing alcohol consumption and the related harms are priorities in national policies in Ireland ${ }^{18} 19$ and many other countries. In the context of the Public Health Alcohol Bill ${ }^{7}$ that is currently going through the Oireachtas (Irish Houses of Parliament), our study highlights the need for wider preventive actions to reduce AR harm outside the health service ${ }^{20}$ and for the development of effective alcohol screening and interventions in EDs and emergency services. ${ }^{21}$ The data collection and policy issues apply in many countries.

The costs of AR presentations are substantial. ${ }^{12}$ We plan to cost the impact of these presentations when a nationally agreed system of costing ED attendances is agreed. We do not know if the burden of AR presentations is increasing - a recent US study has demonstrated that AR $\mathrm{ED}$ visits in that country are increasing at a greater rate than overall ED visits. ${ }^{22}$ We have started to systematically collect AR data on all persons presenting to one of the busiest EDs in the country to assess the prevalence and burden more accurately.

Acknowledgements We thank the staff at all emergency departments in public hospitals in Ireland. We thank the doctors, nurses and other emergency department staff for their work in data collection. We thank Dr David Evans for the help with statistical analysis. We thank the Irish Association of Emergency Medicine for enabling the study, and Dr Diana Egerton-Warburton for invaluable advice.

Contributors BMN, DG and DO'D conceived the research question and designed the data collection instrument. BMN coordinated the data collection through the Irish Association of Emergency Medicine. DG managed the data and carried out the statistical analysis. DO'D wrote the first draft of the manuscript. All authors provided additional intellectual content, contributed to critical revisions of the manuscript, and read and approved the final submitted version. DO'D is the guarantor.

Funding Vouchers for data coordinators were provided by the Health and Wellbeing Division of the Health Service Executive.

Competing interests None declared.

Patient consent Not required.

Ethics approval Research Ethics Committee of the Royal College of Physicians of Ireland.

Provenance and peer review Not commissioned; externally peer reviewed.

Data sharing statement Data from individual hospitals will be made available to staff in those hospitals.

Open Access This is an Open Access article distributed in accordance with the Creative Commons Attribution Non Commercial (CC BY-NC 4.0) license, which permits others to distribute, remix, adapt, build upon this work non-commercially, and license their derivative works on different terms, provided the original work is properly cited and the use is non-commercial. See: http://creativecommons.org/ licenses/by-nc/4.0/

(C) Article author(s) (or their employer(s) unless otherwise stated in the text of the article) 2018. All rights reserved. No commercial use is permitted unless otherwise expressly granted.

\section{REFERENCES}

1. AlcoholAction Ireland. Alcohol and You. http://alcoholireland.ie/ alcohol-and-you/binge-drinking/ (accessed 11 Mar 2018).

2. (accessed 11 Mar 2018)

3. Health Research Board. Alcohol Diary Study 2013. Technical Report. http://www.hrb.ie/uploads/tx_hrbpublications/Alcohol_Diary_Study_ 2013_Technical_Report_web_version_01.pdf (accessed 11 Mar 2017).

4. Hope A, Gill A, Costello G, et al. Alcohol and injuries in the Accident Department: a national perspective. Dublin: Department of Health and Children, 2005.

5. O'Farrell A, Allwright S, Downey J, et al. The burden of alcohol misuse on emergency in-patient hospital admissions among residents from a health board region in Ireland. Addiction 2004;99:1279-85.

6. Hannon MJ, Luke LC. The burden of alcohol misuse on the emergency department. Ir Med J 2006;99:118-20.

7. The Public Health (Alcohol) Bill 2015. http://health.gov.ie/blog/ publications/public-health-alcohol-bill-2015/ (accessed 12 Mar 2018).

8. Intoxicating Liquor Act 2008. http://www.irishstatutebook.ie/eli/2008/ act/17/enacted/en/html (accessed 13 Mar 2018).

9. WHO. ICD-11 Revision. http://www.who.int/classifications/icd/en/ (accessed 11 Mar 2018)

10. Egerton-Warburton D, Gosbell A, Wadsworth A, et al. Survey of alcohol-related presentations to Australasian emergency departments. Med J Aust 2014;201:584-7.

11. Charalambous MP. Alcohol and the accident and emergency department: a current review. Alcohol Alcohol 2002;37:307-12.

12. Parkinson K, Newbury-Birch D, Phillipson A, et al. Prevalence of alcohol related attendance at an inner city emergency department and its impact: a dual prospective and retrospective cohort study. Emerg Med J 2016;33:1-7.

13. Patton R, Green G. Alcohol identification and intervention in English emergency departments. Emerg Med J 2018;35:75-8.

14. Verelst S, Moonen PJ, Desruelles D, et al. Emergency department visits due to alcohol intoxication: characteristics of patients and impact on the emergency room. Alcohol Alcohol 2012;47:433-8.

15. Klein LR, Cole JB, Driver BE, et al. Unsuspected critical illness among emergency department patients presenting for acute alcohol intoxication. Ann Emerg Med 2018;71:279-88.

16. Glencorse M, Wilson G, Birch DN. Paramedic perceptions and attitudes to working with patients with alcohol-related injury or illness. Journal of Paramedic Practice 2014;6:310-8.

17. Crawford MJ, Patton R, Touquet R, et al. Screening and referral for brief intervention of alcohol-misusing patients in an emergency department: a pragmatic randomised controlled trial. Lancet 2004;364:1334-9.

18. Healthy Ireland: a framework for improved health and wellbeing 2013-2025. http://health.gov.ie/wp-content/uploads/2014/03/Heal thylrelandBrochureWA2.pdf (accessed 13 Mar 2018). 
19. Reducing Harm, Supporting Recovery: a health-led response to drug and alcohol use in Ireland 2017-2025. http://health.gov.ie/ wp-content/uploads/2017/07/Reducing-Harm-Supporting-Recovery2017-2025.pdf (accessed 13 Mar 2018).

20. Burton R, Henn C, Lavoie D, et al. A rapid evidence review of the effectiveness and cost-effectiveness of alcohol control policies: an English perspective. Lancet 2017;389:1558-80.
21. Drummond C, Deluca P, Coulton S, et al. The effectiveness of alcohol screening and brief intervention in emergency departments: a multicentre pragmatic cluster randomized controlled trial. PLoS One 2014:9:e99463.

22. Mullins PM, Mazer-Amirshahi M, Pines JM. Alcohol-Related Visits to US Emergency Departments, 2001-2011. Alcohol Alcohol 2017;52:119-25. 